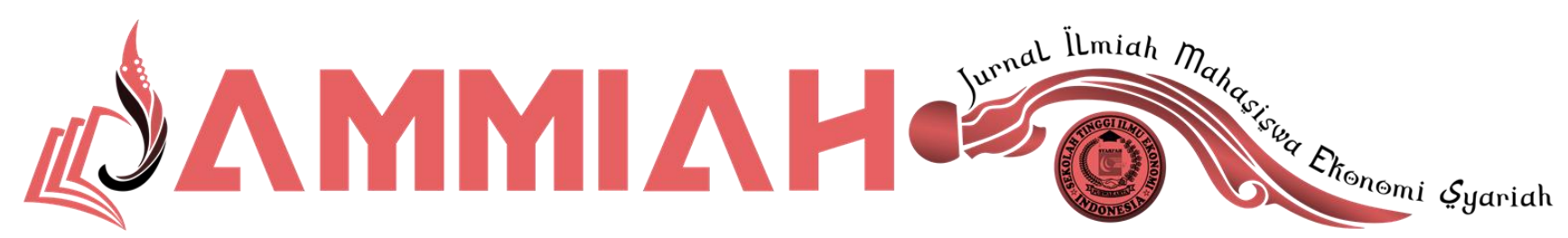

Volume 1 Nomor 2, September 2021

\title{
Analisis Tugas Dan Tanggung Jawab Islami Pada Karyawan Toko Indomaret Veteran 162 Purwakarta
}

\author{
Iwan Gunawan ${ }^{1}$, Siti Hapipah², Ai Siti Khoeriah ${ }^{3}$ \\ ${ }^{1}$ PT. Indomarco Prismatama Cabang Purwakarta \\ 2,3Sekolah Tinggi Ilmu Ekonomi Syariah (STIES) Indonesia Purwakarta \\ 1iwangunawanhdht222@gmail.com \\ 2Sitihapipah009@gmail.com \\ 33isitikhoeriah057@gmail.com
}

\begin{abstract}
ABSTRAK
Tugas dan tanggung jawab karyawan toko adalah uraian pekerjaan yang harus dikerjakan oleh karyawan toko termasuk tanggung jawabnya terhadap barangbarang yang ada di toko. Dalam hal ini, yang penulis fokuskan adalah tugas dan tanggung jawab karyawan toko Indomaret, yang merupakan salah satu ritel minimarket yang terkemuka di Indonesia. Fokus penelitian ini adalah untuk mengetahui tugas dan tanggung jawab karyawan di toko Indomaret Veteran 162 PT. Indomarco Prismatama Cabang Purwakarta, untuk mencari informasi mengenai permasalahan/ kendala yang sering terjadi, dan mencari solusi agar permasalahan pada karyawan di toko Indomaret Veteran 162 PT. Indomarco Prismatama Cabang Purwakarta dapat diselesaikan tanpa harus merugikan siapapun. Adapun hasil dari penelitian ini menunjukan bahwa pembagian tugas dan tanggung jawab karyawan di toko atau gerai Indomaret Veteran 162 sudah sesuai dengan prinsip-prinsip Islam karena tugas yang dikerjakan sesuai dengan jabatan karyawan. Selain itu di Indomaret dalam bekerja benar-benar harus menjunjung tinggi nilai-nilai kejujuran, kebenaran dan keadilan, kerjasam tim, kemajuan melalui inovasi yang ekonomis, serta sangat mengutamakan kepuasan pelanggan dalam segala aspek transaksi yang dilakukan.
\end{abstract}

Kata kunci : Tugas, Tanggung Jawab, Karyawan.

JAMMIAH (Jurnal Ilmiah Mahasiswa Ekonomi Syariah), Volume 1, Nomor 2, September 2021 


\begin{abstract}
The duties and responsibilities of store employees are job descriptions that must be carried out by store employees including their responsibilities for the goods in the store. In this case, what the author focuses on is the duties and responsibilities of Indomaret store employees, which is one of the leading minimarket retailers in Indonesia. The focus of this study was to determine the duties and responsibilities of employees at the Indomaret Veteran 162 PT. Indomarco Prismatama Purwakarta Branch, to find information about problems/constraints that often occur, and find solutions to problems for employees at the Indomaret Veteran 162 store PT. Indomarco Prismatama Purwakarta Branch can be completed without harming anyone. The results of this study indicate that the division of duties and responsibilities of employees at the Indomaret Veteran 162 store or outlet is in accordance with Islamic principles because the tasks carried out are in accordance with the employee's position. In addition, at Indomaret, we really have to uphold the values of honesty, truth and justice, teamwork, progress through economical innovation, and prioritize customer satisfaction in all aspects of the transaction.
\end{abstract}

Keywords: Duties, Responsibilities, Employees.

\title{
I. PENDAHULUAN
}

Dalam upaya menjalankan sebuah usaha, setiap perusahaan pasti memiliki tujuan yang harus dicapai, untuk itu perusahaan akan semakin tergantung pada kualitas sumber daya manusia. Hal ini berarti untuk mencapai kesuksesan dapat diwujudkan dengan cara mengelola sumber daya manusia sebaik-baiknya, karena sumber daya manusia yang berkualitas merupakan salah satu kekuatan yang dimiliki oleh suatu perusahaan untuk mencapai tujuan, salah satunya adalah dengan meningkatkan kinerja karyawan. Setiap perusahaan harus mampu mengembangkan dan meningkatkan perusahaan dengan mengadakan berbagai cara yang tersusun dalam program untuk meningkatkan kinerja para karyawan ${ }^{1}$. Dalam dunia ritel modern saat ini, pembagian tugas dan tanggung jawab karyawan merupakan salah satu strategi perusahaan agar tetap eksis dan bertahan ditengah persaingan usaha yang semakin sengit. Dalam pembagian tugas dan tanggungjawab karyawan tersebut tentu harus menjunjung tinggi rasa keadilan agar tidak ada pihak yang merasa dirugikan. Islam dengan semua ajarannya tentang bermuamalah telah mengatur mengenai kewajiban dan tanggung jawab karyawan agar sesuai dengan prinsipprinsip Islam.

${ }^{1}$ Agus Tunggal Saputra et al., "Pengaruh Kepuasan Kerja Dan Loyalitas Karyawan Terhadap Kinerja Karyawan," Jurnal Manajemen Indonesia 4, no. 1 (2016).

JAMMIAH (Jurnal Ilmiah Mahasiswa Ekonomi Syariah), Volume 1, Nomor 2, September 2021 
Dalam melaksanakan pembagian tugas dan tanggung jawab kepada karyawan perlu diperhatikan bahwa kebugaran fisik sangatlah penting bagi efisiensi karyawan. Seorang karyawan yang sehat dan kuat akan lebih produktif dan efisien daripada karyawan yang lemah dan sakit-sakitan. Demikian pula, karyawan yang dapat dipercaya lagi jujur yang menyadari tugasnya akan lebih komit dan lebih bertanggung jawab dibandingkan dengan karyawan yang tidak jujur ${ }^{2}$.

Penelitaian tentang Analisa Tugas Dan Tanggung Jawab Karyawan sudah banyak dilakukan oleh peneliti sebelumnya seperti yang dilakukan oleh Raras Mayang Arsi, Sri Gunani Partiwi ${ }^{3}$, dalam penelitiannya dijelaskan bahwa beban kerja yang harus ditanggung dalam suatu unit organisasi erat kaitannya dengan efisiensi dan efektivitas suatu perusahaan. Hal ini dikarenakan beban kerja tersebut termasuk pada pengaturan sumber daya manusia yang merupakan sumber daya penting dalam perusahaan. Banyak cara yang dapat dilakukan dalam hal efisiensi sumber daya manusia, antara lain adalah dengan lebih mengoptimalkan jumlah karyawan agar melakukan aktivitas secara tepat. Oleh karena itu diperlukan suatu analisis pengukuran beban kerja untuk menentukan jumlah optimal karyawan yang seharusnya dibutuhkan oleh setiap bidang. Penelitian ini juga hanya mengkaji tentang analisis beban kerja untuk menentukan jumlah optimal karyawan yang dilakukan pada salah satu perguruan tinggi saja tidak pada dunia ritel/ minimarket. Selanjutnya penelitian yang dilakukan oleh Ari Fadzilah4, Tujuan penelitian tersebut adalah untuk meningkatkan kinerja karyawan dalam usaha yang dilakukan oleh perusahaan, maka perusahaan harus melakukan komunikasi secara terbuka dan terus menerus kepada para karyawannya tentang kekuatan, kelemahan pasar, dan tantangan bisnis yang dihadapi serta membangun kepercayaan (trust) dalam organisasi karena pemberdayaan akan dapat berlangsung bila manajer dan karyawan belajar, merasakan melalui pengalaman untuk percaya antara satu sama lain. Dalam penelitian ini, peneliti mengkaji cara-cara perusahaan untuk meningkatkan kinerja karyawan dalam bekerja, tidak mengkaji dan menjelaskan lebih detail tugas dan tanggung jawab karyawan dalam suatu perusahaan.

Peneliti-peneliti sebelumnya banyak yang mengkaji atau meneliti tentang beban kerja yang ditanggung karyawan dalam suatu organisasi yang dilakukan pada suatu

2 Aini Rahmi, "Tanggung Jawab Perusahaan Dan Karyawan Dalam Islam," al-Maslahah; Jurnal Ilmu Syariah 9, no. 2 (2014).

${ }^{3}$ Raras Mayang Arsi and Sri Gunani Partiwi, "Analisis Beban Kerja Untuk Menentukan Jumlah Optimal Karyawan Dan Pemetaan Kompetensi Karyawan Berdasar Pada Job Description (Studi Kasus: Jurusan Teknik Industri, ITS, Surabaya)," Jurnal Teknik ITS 1, no. 1 (2012): A526--A529.

${ }^{4}$ Ari Fadzilah, "Analisis Pengaruh Pemberdayaan Karyawan Dan Self Of Efficacy Terhadap Kinerja Karyawan Bagian Penjualan (Studi Kasus Pada PT. Sinar Sosro Wilayah Pemasaran Semarang)," Jurnal Studi Manajemen Organisasi 3, no. 1 (2006): 12-27.

JAMMIAH (Jurnal Ilmiah Mahasiswa Ekonomi Syariah), Volume 1, Nomor 2, September 2021 
perusahaan dan cara-cara perusahaan untuk meningkatkan kinerja karyawan dalam bekerja. Tidak mengkaji lebih dalam mengenai tugas sebagai karyawan dan tanggung jawab yang harus dijalankan setiap melakukan kegiatan dalam bekerja.

Penelitian ini mengkaji lebih dalam terkait tugas dan tanggung jawab yang dilakukan karyawan dalam bekerja diperusahaan penjualan atau retail, menjelaskan lebih spesifik mengenai permasalahan yang sering terjadi pada perusahaan dan memberikan saran agar mengurangi permasalahan yang sering terjadi.

Fokus penelitian ini adalah untuk mengetahui tugas dan tanggung jawab karyawan di toko Indomaret Veteran 162 PT. Indomarco Prismatama Cabang Purwakarta, untuk mencari informasi mengenai permasalahan/ kendala yang sering terjadi, dan mencari solusi agar permasalahan pada karyawan di toko Indomaret Veteran 162 PT. Indomarco Prismatama Cabang Purwakarta dapat diselesaikan tanpa harus merugikan siapapun.

\section{II.TINJAUAN PUSTAKA}

\section{A. Tanggung Jawab}

\section{Pengertian Tanggung Jawab}

Tanggung jawab merupakan salah satu nilai karakter yang perlu ditanamkan di dalam pribadi setiap manusia, supaya menjadi manusia yang memiliki kepribadian baik. Mustari berpendapat bahwa tanggung jawab adalah sikap dan perilaku seseorang untuk melaksanakan tugas dan kewajiban yang seharusnya dia lakukan, terhadap diri sendiri, masyarakat, lingkungan (alam, sosial dan budaya), negara dan Tuhan ${ }^{5}$.

Sependapat dengan Mustari, Daryanto menyatakan bahwa tangung jawab adalah sikap dan perilaku untuk melaksanakan tugas dan kewajibannya, yang seharusnya dia lakukan, terhadap diri sendiri, masyarakat, lingkungan (alam, sosial, dan budaya), Negara dan Tuhan Yang Maha Esa ${ }^{6}$.

Berdasarkan pengertian-pengertian tanggung jawab di atas, dapat ditarik kesimpulan bahwa tanggung jawab adalah tolak ukur sederhana terhadap sikap dan perilaku seseorang untuk melaksanakan tugas dan kewajibannya.

\section{Macam-macam Tanggung Jawab}

${ }^{5}$ Dian Widiantari, “Analisis Nilai Karakter Melalui Program Vocational Camp Di Madrasah Aliyah Daarul Ulum PUI Majalengka," Eduprof: Islamic Education Journal 2, no. 1 (2020): 1-17.

${ }^{6}$ Moh Sa'i Affan, "Implementasi Kewajiban Orang Tua Tentang Pendidikan Anak Dalam Kompilasi Hukum Islam," An-Nawazil: Jurnal Hukum dan Syariah Kontemporer 2, no. 01 (2020): 76-93.

JAMMIAH (Jurnal Ilmiah Mahasiswa Ekonomi Syariah), Volume 1, Nomor 2, September 2021 
Sukanto mengemukakan bahwa tanggung jawab yang hendaknya ada pada manusia adalah":

a. Tanggung jawab kepada Tuhan yang telah memberikan kehidupan dengan cara takut kepada-Nya, bersyukur dan memohon petunjuk. Semua manusia bertanggung jawab kepada Tuhan Pencipta Alam Semesta.

b. Tanggung jawab untuk membela diri dari ancaman, siksaan, penindasan dan perlakuan kejam dari manapun datangnya.

c. Tanggung jawab diri dari kerakusan ekonomi yang berlebihan dalam mencari nafkah, ataupun sebaliknya, dari bersifat kekurangan ekonomi.

d. Tanggung jawab terhadap anak, suami/istri, dan keluarga.

e. Tanggung jawab terhadap sosial kepada masyarakat sekitar.

f. Tanggung jawab berpikir, tidak perlu mesti meniru orang lain dan menyetujui pendapat umum atau patug secara membuta terhadap niali-nilai tradisi, menyaring segala informasi untuk dipilih, mana yang berguna dan mana yang merugikan mereka.

g. Tanggung jawab dalam memelihara hidup dan kehidupan, termasuk kelestarian lingkungan hidup dari berbagai bentuk pencemaran.

h. Berdasarkan pendapat di atas dapat disimpulkan bahwa tanggung jawab yang menjadi tolak ukur penelitian ini yaitu tanggung jawab belajar yang berpengaruh terhadap prestasi belajar peserta didik.

\section{Ciri-ciri Tanggung Jawab}

Menurut Mustari ciri-ciri tanggung jawab adalah8:

a. Memilih jalan lurus

b. Selalu memajukkan diri sendiri

c. Menjaga kehormatan diri

d. Selalu waspada

e. Memiliki komitmen pada tugas

f. Melakukan tugas dengan standar yang terbaik

g. Mengakui semua perbuatannya

h. Menepati janji

i. Berani menanggung resiko atas tindakan dan ucapannya.

7 Andi Syahraeni, “Tanggung Jawab Keluarga Dalam Pendidikan Anak," Al-Irsyad Al-Nafs: Jurnal Bimbingan dan Penyuluhan Islam 2, no. 1 (2015).

8 Jafar Fathoni, Carolina L Radjah, and Djoko Budi Santoso, "Keefektifan Konseling Singkat Berfokus Solusi Untuk Meningkatkan Tanggung Jawab Belajar Siswa SMA Negeri 7 Kota Kediri," in Prosiding Seminar Nasional Bimbingan Dan Konseling Universitas Negeri Malang, 2020, 30-34.

JAMMIAH (Jurnal Ilmiah Mahasiswa Ekonomi Syariah), Volume 1, Nomor 2, September 2021 
Berdasarkan ciri-ciri tanggung jawab di atas, diharapkan penelitian ini dapat meningkatkan tanggung jawab peserta didik dalam melakukan tugas dangan standar yang baik serta memiliki komitmen pada tugas yang diberikan oleh guru.

\section{Indikator Tanggung Jawab}

Indikator tanggung jawab dalam keberhasilan sekolah dan kelas menurut Daryanto adalah":

a. Indikator tanggung jawab dalam keberhasilan sekolah antara lain:

1) Membuat laporan setiap kegiatan yang dilakukan dalam bentuk lisan maupun tertulis.

2) Melakukan tugas tanpa disuruh

3) Menunjukkan prakarsa untuk mengatasi masalah dalam lingkup terdekat

4) Menghindarkan kecurangan dalam pelaksanaan tugas

b. Indikator tanggung jawab dalam keberhasilan kelas antara lain:

1) Pelaksanaan tugas piket secara teratur

2) Peran serta aktif dalam kegiatan sekolah

3) Mengajukan usul pemecahan masalah

Indikator keberhasilan yang digunakan dalam penelitian ini adalah indikator keberhasilan sekolah. Anak diharapkan nantinya memiliki rasa tanggung jawab yang tinggi antara lain melaksanakan tugas tanpa disuruh dan menghindarkan kecurangan dalam pelaksanaan tugas.

\section{B. Perbandingan Peneliti Terdahulu}

Penelitian tentang Tugas dan Tanggung Jawab karyawan pada suatu perusahaan memang sudah banyak dilakukan oleh peneliti-peneliti sebelumnya seperti yang dilakukan oleh Agiel Puji Damayanti, Susilaningsih, dan Sri Sumaryati10, Hasil dari penelitian menunjukan bahwa adanya pengaruh yang signifikan kompensasi terhadap kinerja perusahaan daerah dan motivasi kerja terhadap kinerja karyawan. Perbedaannya dengan penelitian sekarang adalah mengkaji tugas dan tanggung jawab karyawan pada sebuah perusahaan ritel atau minimarket yang dapat diterapkan juga diperusahaan lainnya.

\footnotetext{
${ }^{9}$ Chairil Faif Pasani, Elli Kusumawati, and Delya Imanisa, "Penerapan Model Pembelajaran Kooperatif Tipe Scramble Dalam Pembelajaran Matematika Untuk Membina Karakter Tanggung Jawab Dan Disiplin Siswa," EDU-MAT: Jurnal Pendidikan Matematika 6, no. 2 (2018).

${ }^{10}$ Agiel Puji Damayanti, Sri Sumaryati, and others, "Pengaruh Kompensasi Dan Motivasi Kerja Terhadap Kinerja Karyawan Perusahaan Daerah Air Minum (PDAM) Surakarta," Jupe-Jurnal Pendidikan Ekonomi 2, no. 1 (2013).
}

JAMMIAH (Jurnal Ilmiah Mahasiswa Ekonomi Syariah), Volume 1, Nomor 2, September 2021 
Selanjutnya penelitian yang dilakukan oleh Anton Nurcahyo ${ }^{11}$, Hasil dari penelitian ini menunjukan bahwa dengan dilakukannya analisis korelasi seperti variable-variabel kompensasi, kepemimpinan, disiplin kerja, kemampuan kerja, motivasi, kondisi kerja dan kerjasama terhadap karyawan akan berpengatuh pada kineja karyawan apabila dibandingkan dengan kinerja karyawan pada perusahan lain. Perbedaan dengan penelitian sekarang adalah lebih fokus menganalisis pembagian tugas dan tanggung jawab karyawan sesuai dengan prinsip-prinsip Islam.

Selanjutnya penelitian yang dilakukan oleh Muhammad Lukman Nasrih ${ }^{12}$, Hasil penelitian menunjukan bahwa hubungan kedua variable yang dijelaskan dalam penelitianya memberikan dampak yang sangat kuat, besarnya korelasi antara kepuasan kerja dengan prestasi kerja dapat berpengaruh terhadap kemajuan suatu perusahaan dalam menjalankan bisnisnya. Perbedaan dengan penelitian sekarang adalah menganalisis kendala-kendala yang sering terjadi pada perusahaan ritel sehingga dapat memberikan dampak negatif terhadap kinerja karyawan dan dapat menimbulkan masalah baru terhadap bisnis yang sedang dijalankan oleh perusahaan.

\section{HASIL DAN PEMBAHASAN}

\section{A.Tugas Dan Tanggung Jawab Islami Pada Karyawan Toko Indomaret Veteran 162 Purwakarta}

Karyawan adalah mereka yang bekerja di suatu perusahaan atau lembaga instansi untuk dapat mengerjakan sebuah tugas dan tanggung jawab operasional dengan mengharapkan balas jasa berupa komisi atau gaji. Sedangkan toko adalah kedai berupa bangunan permanen tempat menjual barang-barang (makanan kecil dan sebagainya). Karyawan memiliki beberapa jenis, diantaranya :

\section{Worker}

Karyawan jenis ini adalah karyawan yang bekerja dengan serius dan benarbenar ingin memberikan kontribusi penting bagi perusahaan atau tempat kerja. Tipe pekerja yang biasanya sangat jujur, disiplin sehingga dapat dijadikan contoh yang baik untuk pekerja lainnya.

\section{Entrepreneur}

Tipe karyawan yang mengejar tujuan yang lebih tinggi, motivasi utama mereka melebihi kebutuhan uang mereka dan mereka memiliki visi dan misi yang jelas dan terarah serta selalu melakukan yang terbaik.

\section{Freeloader}

11 Anton Nurcahyo, "Analisis Variabel-Variabel Yang Mempengaruhi Kinerja Karyawan Pada PT. Quadra Mitra Perkasa Balikpapan," Jurnal Eksis 7, no. 2 (2011): 1972-1982.

12 Muhammad Lukman Nasrih, "Analisis Hubungan Kepuasan Kerja Terhadap Prestasi Kerja Karyawan," Al-Iqtishad: Jurnal Ilmu Ekonomi Syariah 2, no. 1 (2010).

JAMMIAH (Jurnal Ilmiah Mahasiswa Ekonomi Syariah), Volume 1, Nomor 2, September 2021 
Karyawan jenis ini adalah orang yang mencari penghasilan dan tidak peduli dengan pekerjaan. Pekerja jenis ini biasanya sangat antusias dan menarik pada awal pekerjaan mereka. Namun seiring waktu, mereka perlahan-lahan menampakkan sifat aslinya yang selalu menghindari pekerjaan dan bahkan menunjukkan peningkatan kecil ketika diperhatikan.

Tugas adalah perincian tentang kegiatan yang harus dilaksanakan, bagaimana pelaksanaannya dan mengapa tugas itu harus dilaksanakan. Dalam melaksanakan tugas, maka harus dilakukan dengan penuh tanggung jawab. Apa itu tanggung jawab? Tanggung jawab adalah suatu keadaan yang mana seseorang harus menjamin segala sesuatunya, mulai dari proses, hasil akhir, dan sebagainya ${ }^{13}$. Dalam pengertian tanggung jawab, terkandung hal-hal yang mendukung terlaksananya penjaminan bahwa segala sesuatu akan berjalan sesuai dengan yang diharapkannya. Hal-hal tersebut ialah :

1. Hubungan kerja.

Hubunga kerja adalah hubungan antara orang yang bertanggung jawab dengan pihak lain baik didalam maupun diluar organisasi.

2. Kondisi kerja dan perlengkapan yang digunakan.

Kondisi kerja ini menentukan tanggung jawab seorang karyawan. Apabila kondisi kerja kurang memuaskan, maka proses pertanggung jawaban itu tidak terlaksana dengan baik.

Hal-hal diatas sangat berpengaruh terhadap kinerja kerja karyawan. Kinerja kerja karyawan adalah hasil kerja yang dicapai seseorang atau kelompok orang sesuai dengan wewenang atau tanggung jawab masing-masing karyawan selama periode tertentu ${ }^{14}$. Berdasarkan pengertian diatas dapat diambil kesimpulan bahwa tugas dan tanggungjawab karyawan toko adalah uraian pekerjaan yang harus dikerjakan oleh karyawan toko termasuk tanggung jawabnya terhadap barangbarang yang ada di toko. Dalam hal ini, yang penulis fokuskan adalah tugas dan tanggung jawab karyawan toko Indomaret, yang merupakan salah satu ritel mini market yang terkemuka di Indonesia.

Dalam Islam pekerja atau karyawan termasuk salah satu daripada perhiasanperhiasan yang menghiasi indahnya dunia. Maksudnya, pegawai menjadi bagian penting tegaknya suatu masyarakat dan Negara. Tanpa pegawai urusan-urusan

${ }^{13}$ Eny Rohyati, “Penyusunan Tugas Dan Tanggungjawab Karyawan Pada Universitas X," Jurnal Psikologi 12, no. 1 (2019).

${ }_{14}$ Tri Wartono, "Pengaruh Stres Kerja Terhadap Kinerja Karyawan (Studi Pada Karyawan Majalah Mother And Baby)," KREATIF: Jurnal Ilmiah Prodi Manajemen Universitas Pamulang 4, no. 2 (2017).

JAMMIAH (Jurnal Ilmiah Mahasiswa Ekonomi Syariah), Volume 1, Nomor 2, September 2021 
kemasyarakatan, bangsa dan Negara tidak akan berjalan dengan baik. Seorang ahli hikmah mengatakan, "Dunia ini ibarat taman yang indah yang dihiasi dengan lima perkara: Ilmu para ulama, keadilan para pemimpin, ibadah para hamba, amanat para pengusaha dan kejujuran para pekerja.

Sebagai pekerja kita harus memiliki prinsip-prinsip dalam bekerja sebagai perisai kita dalam bekerja sehingga terhindar dari hal-hal yang dilarang oleh Islam. Adapun prinsip-prinsip bekerja adalah sebagai berikut.

1. Niat bekerja adalah untuk beribadah kepada Allah. Sebagaimana firman Allah SWT dalam Al-Qur'an :

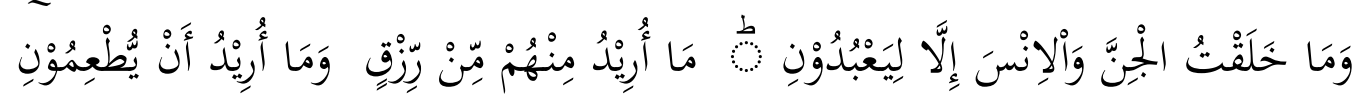

“Dan Aku tidak menciptakan jin dan manusia melainkan supaya mereka menyembahKu. Aku tidak menghendaki rizki sedikitpun dari mereka dan aku tidak menghendaki supaya mereka memberi Aku makan". (QS. Adzariat: 56-57).

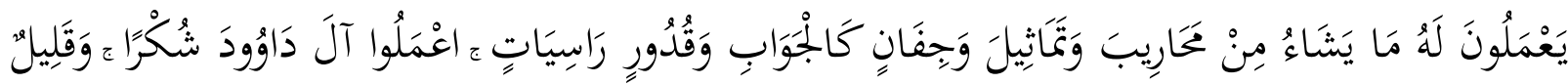
مِنْ عِبَادِيَ الشَّكُورُ

"Para jin itu membuat untuk Sulaiman apa yang dikehendakinya dari gedung-gedung yang tinggi dan patung-patung dan piring-piring yang (besarnya) seperti kolam dan periuk yang tetap (berada di atas tungku). Bekerjalah hai keluarga Daud untuk bersyukur (kepada Allah). Dan sedikit sekali dari hamba-hamba-Ku yang berterima kasih". (QS. Saba': 13).

Ayat tersebut menjelaskan tentang perintah bekerja sebagai tanda syukur kepada Allah.

2. Kerja adalah untuk memakmurkan alam semesta. Sebagaimana firman Allah SWT dalam Al-Qur'an :

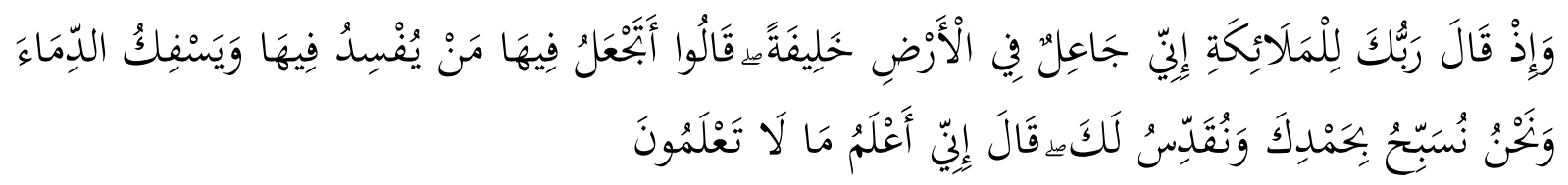

"Dan Ingatlah ketika Tuhanmu berfirman kepada para malaikat: "Sesungguhnya Aku hendak menjadikan seorang khalifah di muka bumi". Mereka berkata: "Mengapa Engkau hendak menjadikan (khalifah) di bumi itu orang yang akan membuat kerusakan padanya dan menumpahkan darah, padahal kami senantiasa bertasbih dengan memuji Engkau dan menyucikan Engkau?" Tuhan berfirman: "Sesungguhnya Aku mengetahui apa yang tidak kamu ketahui". (QS. Al-Baqarah : 30)15.

${ }^{15}$ M Mukhid Mashuri and Ibnu Romadon, “Khalifah Di Bumi Sebelum Nabi Adam AS. (Tafsir Tematik QS. Al Baqarah: 30)," Mafhum 4, no. 1 (2019): 75-94.

JAMMIAH (Jurnal Ilmiah Mahasiswa Ekonomi Syariah), Volume 1, Nomor 2, September 2021 


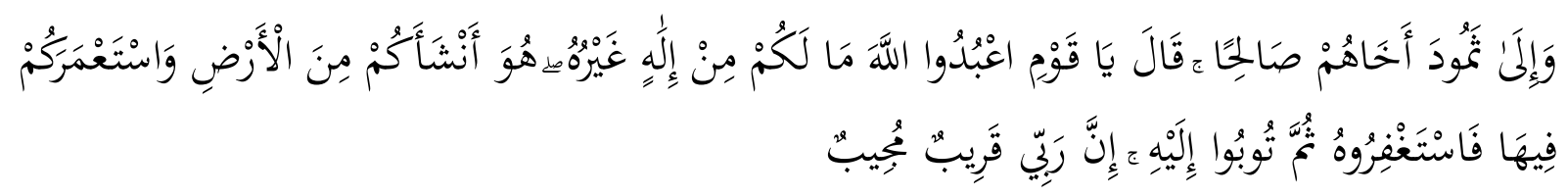

"Dan kepada Tsamud (Kami utus) saudara mereka Shaleh. Shaleh berkata: Hai kaumku, sembahlah Allah, sekali-kali tidak ada bagimu Tuhan selain Dia. Dia telah menciptakan kamu dari bumi (tanah) dan menjadikan kamu pemakmurnya, karena itu mohonlah ampunan-Nya, kemudian bertobatlah kepada-Nya. Sesungguhnya Tuhanku amat dekat (rahmat-Nya) lagi memperkenankan (doa hamba-Nya)". (QS. Hud : 61) ${ }^{16}$.

Firman Allah yang menyebutkan bahwa barangsiapa yang bercocok tanam disini, maka ia akan menikmati hasilnya disana, apa saja yang ia kerjakan di sana akan diberi imbalan. Dengan demikian manusia dituntut untuk tahu tujuan hidupnya dan rahasia dibalik penciptaannya. Manusia diciptakan Allah untuk menjadi hamba Allah yang memimpin alam bukan untuk menjadi hamba dari yang diciptakan-Nya.

3. Tujuan dan orientasi bekerja adalah sebagai investasi amal shaleh untuk kebahagiaan hidup di akhirat sekaligus kebahagian hidup di dunia terpenuhi keseimbangan kebutuhan jasmani dan rohani. Sebagaimana firman Allah SWT dalam Al-Qur'an :

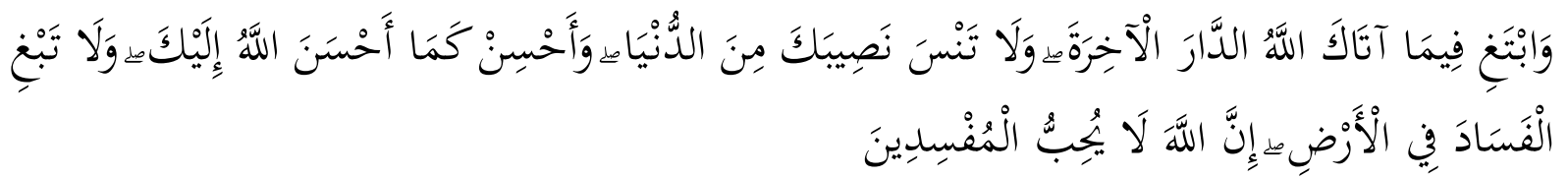

"Dan carilah pada apa yang telah dianugerahkan Allah kepadamu (kebahagiaan) negeri akherat dan janganlah kamu melupakan bagianmu dari (kenikmatan) duniawi dan berbuat baiklah (kepada orang lain) sebagaimana Allah telah berbuat baik kepadamu, dan janganlah kamu berbuat kerusakan di muka bumi. Sesungguhnya Allah tidak menyukai orang-orang yang berbuat kerusakan". (QS. Al-Qashas : 77) ${ }^{17}$.

4. Bekerja pada bidang-bidang yang baik serta menghindari segala yang diharamkan kotor (keji). Sebagaimana firman Allah SWT dalam Al-Qur'an :

${ }^{16}$ Husnul Amin, “Integrasi Pendidikan Islam," Raudhah Proud To Be Professionals: Jurnal Tarbiyah Islamiyah 2, no. 1 (2017): 103-110.

${ }_{17}$ Rahendra Maya, "Pemikiran Al-Sa'di Tentang Kriteria Pegawai Profesional (Studi Terhadap QS AlQashash [28]: 26, Hadits-Hadits Terkait, Dan Kajian Lainnya)," Ad-Deenar: Jurnal Ekonomi dan Bisnis Islam 2, no. 01 (2018): 1-24.

JAMMIAH (Jurnal Ilmiah Mahasiswa Ekonomi Syariah), Volume 1, Nomor 2, September 2021 


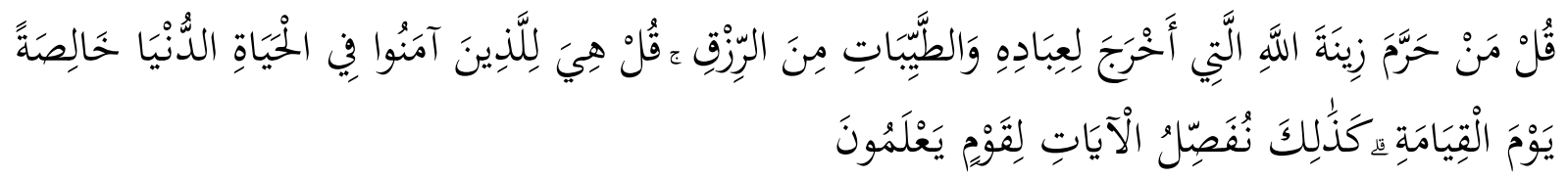

"Katakanlah : siapakah yang mengharamkan perhiasan dari Allah yang telah dikeluarkan-Nya untuk hamba-hamba-Nya dan (siapa pulakah yang mengharamkan) rizki yang baik "Katakanlah: semuanya itu disediakan bagi orang-orang yang beriman dalam kehidupan dunia, khusus (untuk mereka saja) di hari kiamat". (QS. Al-a'raf : 32).

Telah sampai kepada kita dari Muhammad SAW bahwa beliau bersabda: "Sungguh, seorang hamba memasukkan satu suap makanan haram ke perutnya, Allah SWT tidak menerima amalnya selama empat puluh hari, dan siapapun seorang hamba yang dagingnya tumbuh dari sesuatu yang haram, maka neraka lebih baik baginya ". (HR Ath -Thabrani)

5. Mengangkat dan mendelegasikan pekerjaan pada ahlinya (cakap). Sebagaimana firman Allah SWT dalam Al-Qur'an :

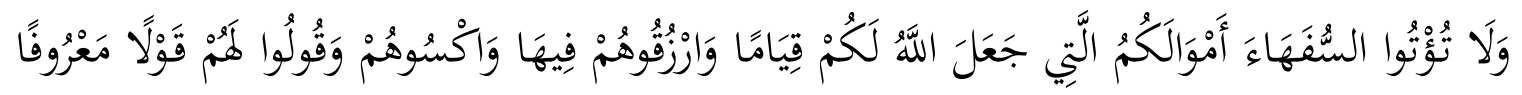

"Dan janganlah kamu serahkan kepada orang-orang yang belum sempurna akalnya, harta (mereka yang dalam kekuasaanmu) yang dijadikan Allah sebagai pokok kehidupan. Berilah mereka belanja dan pakaian (dari harta itu) dan ucapkanlah kepada mereka katakata yang baik". (QS. An-nisa' : 5) ${ }^{18}$.

6. Membayar zakat adalah perintah yang dapat mensucikan harta. Sebagaimana firman Allah SWT dalam Al-Qur'an :

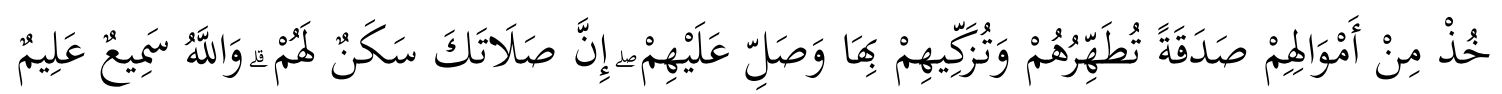

"Ambillah zakat dari sebagian harta mereka dengan zakat itu kamu membersihkan dan mensucikan mereka, dan berdo'alah untuk mereka, sesungguhnya do'a kamu itu (menjadi) ketentraman jiwa bagi mereka". (QS. At-Taubah : 103) ${ }^{19}$.

\section{B. Kendala / permasalahan yang sering terjadi pada karyawan toko Indomaret Veteran 162 PT. Indomarco Prismatama Cabang Purwakarta}

Dalam melakukan tugas dan tanggung jawab islami karyawan yang dilakukan di toko Indomaret Veteran 162 PT. Indomarco Prismatama Cabang Purwakarta, memiliki beberapa kendala, diantaranya :

${ }^{18}$ M Zaid Su'di, “Terjemah Edip Yuksel, Dkk. Atas QS An-Nisa [4]: 2-6,” Al Furqan: Jurnal Ilmu Al Quran dan Tafsir 2, no. 1 (2019): 65-75.

${ }^{19}$ Sri Riwayati, “Zakat Dalam Telaah Qs. At-Taubah: 103,” Al Furqan: Jurnal Ilmu Al Quran dan Tafsir 1, no. 2 (2018): 77-91.

JAMMIAH (Jurnal Ilmiah Mahasiswa Ekonomi Syariah), Volume 1, Nomor 2, September 2021 
a) Membayar Variance Minus

Variance minus adalah selisih penggantian dimana fisik uang yang ada di laci transaksi berbeda dengan data komputer. Biasanya terjadi karena beberapa hal, yaitu tidak memastikan uang modal dihitung dengan benar, perbedaan harga antara di rak display dengan di pos transaksi yang selisihnya menjadi beban kasir, penukaran uang kecil tidak dihitung lagi, dan salah pengembalian kepada pelanggan.

b) Komplain Pelanggan

Biasanya terjadi ketika ada perbedaan harga antara di price tag dengan di pos transaksi. Hal itu terjadi karena ada kesalahan data komputer, store crew belum melakukan update harga terbaru dan melakukan cetak dan memasang harga terbaru di komputer.

c) Sulit Menentukan Prioritas Target Kerja

Banyaknya pekerjaan yang harus dilakukan oleh karyawan toko ketika toko ramai biasanya akan menghambat pekerjaan utamanya, sehingga mau tidak mau harus megutamakan pelayanan kepada pelanggan.

d) Kendala Sarana dan Prasarana

1) Komputer error ketika pelanggan antri, menyebabkan manual sales yang berpotensi variance minus atau plus karena kurang teliti administrasi.

2) AC toko panas yang menyebabkan pelanggan kurang nyaman belanja di toko Indomaret.

3) Toko bocor ketika terjadi hujan deras yang menyebabkan kondisi toko basah dan menganggu aktivitas belanja pelanggan.

\section{Pemecahan Masalah pada karyawan toko Indomaret Veteran 162 PT. Indomarco Prismatama Cabang Purwakarta}

Masalah-masalah yang terjadi di toko Indomaret Veteran 162 yang telah diuraikan diatas tentu harus dicari cara penyelesaiannya agar pelayanan terhadap pelanggan tidak terganggu dan pelanggan merasa puas belanja di toko. Adapun beberapa problem solving atas masalah-masalah tersebut adalah sebagai berikut :

a) Membayar Variance Minus

Agar tidak terjadi variance minus antisipasi yang dapat dilakukan oleh store crew adalah pastikan uang modal yang diterima dari pimpinan shift dihitung dengan benar, jika kurang langsung infokan ke pimpinan shift, pastikan ketika ada penukaran uang kecil dihitung dengan benar, pastikan sudah update harga, pastikan uang modal dan setoran sales dicatat di buku monitoring modal dan setoran, dan selalu teliti ketika memberikan uang 
kembalian kepada pelanggan dengan cara menyebutkan nominal uang yang diberikan.

b) Komplain Pelanggan

Agar tidak terjadi komplain pelanggan, pastikan store crew sudah melakukan update harga setiap shift 1, update harga promosi, ketika terjadi komplain pelanggan pastikan diselesaikan secara baik-baik, karena pelanggan berhak mendapatkan harga terendah ketika terjadi selisih harga. Karena hal itu sudah menjadi ketentuan dari perusahaan.

c) Sulit Menentukan Prioritas Target Kerja

Kerja di toko itu penuh dengan tantangan karena berhadapan langsung dengan pelanggan yang memiliki latar belakang yang berbeda-beda. Pelanggan yang datang ke toko kadang-kadang ada yang jutek, ada yang buru-buru, ada yang ramah, dan ada juga yang santai. Oleh karena itu karyawan toko harus selalu mengedepankan pelayan tulus dan bersahabat terhadap pelanggan, lakukan 5S (senyum, salam, sapa, dengan sopan dan santun). Ketika masuk berdua pastikan pembagian tugas kerja dilakukan secara jelas dan adil. Karena kerja di toko itu harus mengedepankan kerjasama tim yang baik.

d) Kendala Sarana dan Prasana

1) Komputer Error, biasanya terjadi karena mati lampu. Oleh karena itu pastikan ketersedian bahan bakar untuk genset ada, sehingga ketika terjadi mati lampu karyawan toko dapat langsung menyalakan genset, dan pelanggan tidak terlalu lama menunggu untuk melakukan pembayaran di pos transaksi.

2) AC toko panas, biasanya terjadi karena AC belum di service. Oleh karena itu lakukan complain online dan infokan ke Area Supervisor agar segera dilakukan perbaikan oleh tim service AC.

3) Toko Bocor, biasanya terjadi karena kemarau panjang lalu tiba-tiba hujan deras dan tim toko belum sempat melakukan pengecekan terhadap area yang rawan bocor. Solusinya infokan ke pihak Area Supervisor dan lakukan complain online di komputer toko, agar segera dilakukan perbaikan oleh pihak terkait (Maintenance).

\section{KESIMPULAN}

Berdasarkan pengumpulan data yang diteliti oleh penulis mengenai Analisa Tugas Dan Tanggung Jawab Islami Karyawan Toko Indomaret Veteran 162 PT. Indomarco Prismatama Cabang Purwakarta, penulis meyakini bahwa pembagian 
tugas dan tanggungjawab karyawan di toko atau gerai Indomaret Veteran 162 sudah sesuai dengan prinsip-prinsip Islam karena tugas yang dikerjakan sesuai dengan jabatan karyawan. Dan di Indomaret dalam bekerja benar-benar harus menjunjung tinggi nilai-nilai kejujuran, kebenaran dan keadilan, kerjasama tim, kemajuan melalui inovasi yang ekonomis, serta sangat mengutamakan kepuasan pelanggan dalam segala aspek transaksi yang dilakukan.

Dalam melakukan tugas dan tanggung jawab karyawan toko Indomaret Veteran 162 PT. Indomarco Prismatama Cabang Purwakarta, memiliki beberapa kendala, diantaranya : a) Membayar Variance Minus, b) Komplain Pelanggan, c) Sulit Menentukan Prioritas Target Kerja, d) Kendala Sarana dan Prasarana, 1) Komputer error ketika pelanggan antri, menyebabkan manual sales yang berpotensi variance minus atau plus karena kurang teliti administrasi; 2) AC toko panas yang menyebabkan pelanggan kurang nyaman belanja di toko Indomaret; 3) Toko bocor ketika terjadi hujan deras yang menyebabkan kondisi toko basah dan menganggu aktivitas belanja pelanggan.

Masalah-masalah yang terjadi di toko Indomaret Veteran 162 yang telah diuraikan diatas tentu harus dicari cara penyelesaiannya agar pelayanan terhadap pelanggan tidak terganggu dan pelanggan merasa puas belanja di toko. Adapun beberapa problem solving atas masalah-masalah tersebut adalah sebagai berikut : a) Membayar Variance Minus, memastikan uang modal yang diterima dari pimpinan shift dihitung dengan benar, pastikan ketika ada penukaran uang kecil dihitung dengan benar, pastikan sudah update harga, pastikan uang modal dan setoran sales dicatat di buku monitoring modal dan setoran, dan selalu teliti ketika memberikan uang kembalian kepada pelanggan dengan cara menyebutkan nominal uang yang diberikan; b) Komplain Pelanggan, pastikan store crew sudah melakukan update harga setiap shift 1, update harga promosi, ketika terjadi komplain pelanggan pastikan diselesaikan secara baik-baik; c) Sulit Menentukan Prioritas Target Kerja, karyawan toko harus selalu mengedepankan pelayanan tulus dan bersahabat terhadap pelanggan, lakukan 5S (senyum, salam, sapa, dengan sopan dan santun); d) Kendala Sarana dan Prasana, 1) Komputer Error, pastikan ketersedian bahan bakar untuk genset ada, sehingga ketika terjadi mati lampu karyawan toko dapat langsung menyalakan genset, dan pelanggan tidak terlalu lama menunggu untuk melakukan pembayaran di pos transaksi. 2) AC toko panas, lakukan complain online dan infokan ke Area Supervisor agar segera dilakukan perbaikan oleh tim service AC. 3) Toko Bocor, Solusinya infokan ke pihak Area Supervisor dan lakukan complain online di komputer toko, agar segera dilakukan perbaikan oleh pihak terkait (Maintenance). 
Peneliti menyarankan kepada seluruh karyawan toko tersebut agar ketika bekerja dan menjalankan tugas dan tanggungjawabnya hendaknya selalu menjunjung tinggi nilai-nilai kejujuran, kebenaran dan keadilan. Selalu bekerjasama dalam bekerja, dan utamakan pelanggan dalam melakukan pelayanan sesuai dengan nila-nilai budaya kerja perusahaan yang wajib dijalankan oleh seluruh karyawan Indomaret. Karena Islam sangat menjunjung tinggi nila-nilai positif tersebut. Serta selalu awali dengan do'a ketika kita mulai bekerja agar pekerjaan yang kita lakukan bernilai ibadah dan mendapatkan berkah dari Allah SWT. Amiin.

\section{DAFTAR PUSTAKA}

Affan, Moh Sa'i. "Implementasi Kewajiban Orang Tua Tentang Pendidikan Anak Dalam Kompilasi Hukum Islam." An-Nawazil: Jurnal Hukum dan Syariah Kontemporer 2, no. 01 (2020): 76-93.

Amin, Husnul. "Integrasi Pendidikan Islam." Raudhah Proud To Be Professionals: Jurnal Tarbiyah Islamiyah 2, no. 1 (2017): 103-110.

Arsi, Raras Mayang, and Sri Gunani Partiwi. "Analisis Beban Kerja Untuk Menentukan Jumlah Optimal Karyawan Dan Pemetaan Kompetensi Karyawan Berdasar Pada Job Description (Studi Kasus: Jurusan Teknik Industri, ITS, Surabaya)." Jurnal Teknik ITS 1, no. 1 (2012): A526--A529.

Damayanti, Agiel Puji, Sri Sumaryati, and others. "Pengaruh Kompensasi Dan Motivasi Kerja Terhadap Kinerja Karyawan Perusahaan Daerah Air Minum (PDAM) Surakarta." Jupe-Jurnal Pendidikan Ekonomi 2, no. 1 (2013).

Fadzilah, Ari. "Analisis Pengaruh Pemberdayaan Karyawan Dan Self Of Efficacy Terhadap Kinerja Karyawan Bagian Penjualan (Studi Kasus Pada PT. Sinar Sosro Wilayah Pemasaran Semarang)." Jurnal Studi Manajemen Organisasi 3, no. 1 (2006): 12-27.

Fathoni, Jafar, Carolina L Radjah, and Djoko Budi Santoso. "Keefektifan Konseling Singkat Berfokus Solusi Untuk Meningkatkan Tanggung Jawab Belajar Siswa SMA Negeri 7 Kota Kediri." In Prosiding Seminar Nasional Bimbingan Dan Konseling Universitas Negeri Malang, 30-34, 2020.

Mashuri, M Mukhid, and Ibnu Romadon. "Khalifah Di Bumi Sebelum Nabi Adam AS. (Tafsir Tematik QS. Al Baqarah: 30)." Mafhum 4, no. 1 (2019): 75-94.

Maya, Rahendra. "Pemikiran Al-Sa'di Tentang Kriteria Pegawai Profesional (Studi Terhadap QS Al-Qashash [28]: 26, Hadits-Hadits Terkait, Dan Kajian Lainnya)." Ad-Deenar: Jurnal Ekonomi dan Bisnis Islam 2, no. 01 (2018): 1-24.

JAMMIAH (Jurnal Ilmiah Mahasiswa Ekonomi Syariah), Volume 1, Nomor 2, September 2021 http://journal.sties-purwakarta.ac.id/index.php/jammiah/ ISSN: 2797-040X (Media Online) 2797-197X (Media Cetak) 
Nasrih, Muhammad Lukman. "Analisis Hubungan Kepuasan Kerja Terhadap Prestasi Kerja Karyawan.” Al-Iqtishad: Jurnal Ilmu Ekonomi Syariah 2, no. 1 (2010).

Nurcahyo, Anton. "Analisis Variabel-Variabel Yang Mempengaruhi Kinerja Karyawan Pada PT. Quadra Mitra Perkasa Balikpapan." Jurnal Eksis 7, no. 2 (2011): 1972-1982.

Pasani, Chairil Faif, Elli Kusumawati, and Delya Imanisa. "Penerapan Model Pembelajaran Kooperatif Tipe Scramble Dalam Pembelajaran Matematika Untuk Membina Karakter Tanggung Jawab Dan Disiplin Siswa." EDU-MAT: Jurnal Pendidikan Matematika 6, no. 2 (2018).

Rahmi, Aini. "Tanggung Jawab Perusahaan Dan Karyawan Dalam Islam." alMaslahah; Jurnal Ilmu Syariah 9, no. 2 (2014).

Riwayati, Sri. "Zakat Dalam Telaah Qs. At-Taubah: 103." Al Furqan: Jurnal Ilmu Al Quran dan Tafsir 1, no. 2 (2018): 77-91.

Rohyati, Eny. "Penyusunan Tugas Dan Tanggungjawab Karyawan Pada Universitas X." Jurnal Psikologi 12, no. 1 (2019).

Saputra, Agus Tunggal, I Wayan Bagia, Ni Nyoman Yulianthini, and M M SE.

"Pengaruh Kepuasan Kerja Dan Loyalitas Karyawan Terhadap Kinerja Karyawan." Jurnal Manajemen Indonesia 4, no. 1 (2016).

Su'di, M Zaid. “Terjemah Edip Yuksel, Dkk. Atas QS An-Nisa [4]: 2-6." Al Furqan: Jurnal Ilmu Al Quran dan Tafsir 2, no. 1 (2019): 65-75.

Syahraeni, Andi. “Tanggung Jawab Keluarga Dalam Pendidikan Anak.” Al-Irsyad AlNafs: Jurnal Bimbingan dan Penyuluhan Islam 2, no. 1 (2015).

Wartono, Tri. "Pengaruh Stres Kerja Terhadap Kinerja Karyawan (Studi Pada Karyawan Majalah Mother And Baby)." KREATIF: Jurnal Ilmiah Prodi Manajemen Universitas Pamulang 4, no. 2 (2017).

Widiantari, Dian. “Analisis Nilai Karakter Melalui Program Vocational Camp Di Madrasah Aliyah Daarul Ulum PUI Majalengka." Eduprof: Islamic Education Journal 2, no. 1 (2020): 1-17. 